\title{
A calculator program for clinical application of the Bayesian method of predicting plasma drug levels
}

\author{
Stefano Ruffo ${ }^{1}$, Andrea Messori ${ }^{2}$, Thaddeus H. Grasela ${ }^{4}$, Giovanni Longo ${ }^{3}$, \\ Giancarlo Donati-Cori ${ }^{2}$, Marzia Matucci ${ }^{3}$, Massimo Morfini ${ }^{3, *}$ and Enrico Tendi ${ }^{2}$ \\ I Department of Physics, University of Florence, Florence, ${ }^{2}$ Hospital Pharmacy, and ${ }^{3}$ Hemophilia Center, USL 10/D, Ospedale di \\ Careggi, Viale Morgagni 85, 50134 Florence, Italy and ${ }^{4}$ Department of Pharmacy Services and College of Pharmacy, The University of \\ Michigan Hospitals, Ann Arbor, MI, U.S.A.
}

\begin{abstract}
A pharmacokinetic program that allows individualization of drug dosage regimens through the Bayesian method is described. The program, which is designed for the Hewlett-Packard HP-41 CV calculator, is based upon the one-compartment open model with either instantaneous or zero-order absorption. Individualized estimation of the patient's kinetic parameters (clearance and volume of distribution) is performed by analyzing the plasma levels measured in the patient as well as considering the population data of the drug. After estimating the individual kinetic parameters by the Bayesian method, the program predicts the dosage regimen that will elicit the desired peak and trough plasma levels at steady state. For comparison purposes, the least-squares estimates for clearance and volume of distribution are calculated, and dosage prediction can also be made on the basis of the least-squares estimates. The least-squares estimates can be used to calculate population pharmacokinetic parameters according to the Standard Two-Stage method.

Several examples of clinical use of the program are presented. The examples refer to patients with classic hemophilia who were treated with Factor VIII concentrates. In these patients, the Bayesian kinetic parameters of Factor VIII have been estimated through the calculator program. The Bayesian parameter estimates generated by the HP-41 have been compared with those determined by a Bayesian program (ADVISE) designed for microcomputers.
\end{abstract}

Pharmacokinetics Calculators Automation Data processing Factor VIII Hemophilia Drug dosage calculations

\section{INTRODUCTION}

The Bayesian method [1,2] is a relatively recent technique for predicting plasma drug levels and individualizing dosage regimens. This technique has an important advantage in that it exploits the information resulting from the plasma levels which have been measured in the patient concerned, as well as information about the kinetic response to the drug observed in patient populations previously treated with the drug. Thus, the main feature of the Bayesian method is that both individual and

\footnotetext{
* To whom all correspondence should be sent.
}

population kinetic data contribute to the estimation of the best-fit kinetic parameters for a given patient. Conversely, the older kinetic techniques for individualizing the dosage regimen of drugs [3-7] were only based upon the plasma levels measured in the patient.

The Bayesian method can be applied in clinical practice by using a number of computer programs [8-12]. Among these, the ADVISE program [12], designed for the Hewlett-Packard HP-85/87 microcomputer, is one of the most commonly used.

During the past five years, low-cost hand-held calculators have been widely used for pharmacokinetic applications [13-24]. The Hewlett-Packard 
HP-41 model is the hand-held calculator for which the largest number of programs have been published [16-24]. In light of the growing interest of clinicians in using hand-held calculators for pharmacokinetics, we have developed an HP-41 calculator program that allows for clinical use of the Bayesian method.

Although our HP-41 program employs the linearized Bayesian method in its simplest implementation for the one-compartment model, this calculator program performs essentially the same functions as the original HP-85/87 computer program. The data of 12 hemophiliacs treated with Factor VIII concentrates have been used to demonstrate the clinical application of the HP-41 Bayesian program. Finally, in Appendix 3 it is shown that the program can also be used to obtain population pharmacokinetic parameters according to the Standard Two-Stage method.

\section{THEORY}

Our HP-41 program is based on the one-compartment kinetic model with instantaneous absorption. The equation for such model is the following:

$C_{\mathrm{p}}=\frac{D}{V d} e^{-(C L / V d) t}$

where:

$C_{\mathrm{p}}$ is the plasma level at the time $t$;

$t$ is the time elapsed after the dose;

$C L$ is the clearance;

$D$ is the administered dose;

$V d$ is the apparent volume of distribution.

When repeated doses are given, the time-course of plasma levels can be calculated by application of the superposition principle [25].

As shown in Appendix 1, our program is designed in such a way that the user may select the one-compartment model with zero-order input when necessary. The selection of the latter model is needed in those cases (e.g. administration of the drug by oral route or by constant-rate intravenous infusion) where the drug absorption cannot be assumed to be instantaneous.
The current presentation of our procedure is focused on the application of the Bayesian method to the kinetics of Factor VIII. Since the one-compartment model with instantaneous absorption is appropriate for Factor VIII [26], only the use of the one-compartment model with zero-order input is discussed in Appendix 1.

Before presenting our simplified Bayesian procedure, the original Bayesian feedback method, as implemented by Sheiner in the ADVISE computer program [12], will be briefly described.

\subsection{The theoretical basis of the ADVISE program}

Given a set of $n$ plasma concentrations measured in a patient, the Bayesian feedback method performs estimation of the best-fit values of the one-compartment kinetic variables (namely $C L$ and $V d$ ). Such estimation can be performed with regard to any dosage regimen and any combination of plasma samplings. The Bayesian method determines the best-fit parameter estimates by using population and individual kinetic data. The population average values of the kinetic parameters must therefore be known, along with their interindividual standard deviations. The value of the residual intraindividual and model misspecification error variability, as previously defined $[27,28]$, must be known as well. The HP-85/87 Bayesian procedure performs estimation of the one-compartment kinetic parameters from the plasma level data by using a simple algorithm. In such estimation, the ADVISE program can model the absorption process either as an instantaneous or as a zero-order process; under the latter circumstance, the user must provide an estimate of the period $(T)$ over which the zero-order absorption occurs since the computer program is unable to calculate an estimate of this parameter.

\subsection{The theoretical basis of the HP.4I program}

The program input consists of the following data:

Administered doses $\left(D_{j}\right)$ and times $\left(t_{D_{j}}\right)$ at which the doses were given.

Measured plasma concentrations $\left(C_{i}\right)$ and times $\left(t_{C i}\right)$ at which the concentrations were measured. 
Population average values for $C L$ and $V d\left(C L_{\text {pop }}\right.$ and $\left.V_{\mathrm{pop}}\right)$ and respective standard deviations $\left(\mathrm{SD}_{\mathrm{CL}}\right.$ and $\mathrm{SD}_{\mathrm{v}}$ ).

Coefficient of variation for residual error $\left(C V_{\mathrm{RE}}\right)$; the residual error (RE) refers to the intraindividual and model misspecification error variability.

All time values are entered as date and hour: the day on which the first dose was given is arbitrarily designated as 'day l'; the code for all subsequent days is defined accordingly.

In the framework of the Bayesian theory, our HP-41 program employs a linear approximation method to calculate the best-fit estimates of $C L$ and $V d$ from the measured plasma levels. This method proceeds by the following steps:

(a) Initialize: set $C L$ and $V d$ to population average values and $C V_{\mathrm{RE}}$ to the population value of the coefficient of variation for RE. Also set: $i=0, w_{11}=\mathrm{SD}_{\mathrm{V}}^{2}, w_{22}=\mathrm{SD}_{\mathrm{CL}}^{2}$ and $w_{12}=0$.

(b) Store: all values of $D_{j}$ and $t_{D j}$ in program memory.

(c) Set: $i=i+1$

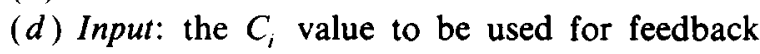
adjustment of $C L$ and $V d$; if none, exit.

(e) Compute:

$C_{f i}=\sum_{j=1}^{r} \frac{D_{j} \cdot \exp \left(-[C L / V d]\left[t_{C i}-t_{D_{j}}\right]\right)}{V d}$

where $C_{f i}$ is the fitted value of concentration and $r$ is the number of dose values for which $t_{D j}$ is less than $t_{C i}$.

( $f$ ) Compute:

$$
\begin{aligned}
c_{V i}= & \sum_{j=1}^{r}\left\{\left(D_{j} \cdot \exp \left(-[C L / V d]\left[t_{C i}-t_{D_{j}}\right]\right)\right)\right. \\
& \left.\times\left(C L\left[t_{C i}-t_{D j}\right]-V d\right) / V d^{3}\right\} \\
c_{C L i}= & \sum_{j=1}^{r}\left\{\left(D_{j} \cdot \exp \left(-[C L / V d]\left[t_{C i}-t_{D j}\right]\right)\right)\right. \\
& \left.\times\left(t_{D j}-t_{C i}\right) / V d^{2}\right\} \\
E_{i}= & C_{i}-C_{f i}
\end{aligned}
$$

where $c_{V i}$ and $c_{C L i}$ are the partial derivatives of $C_{\mathrm{p}}$ with respect to $V d$ and $C L$, respectively. (g) Compute:

$$
\begin{aligned}
& d=w_{11} w_{22}-w_{12}^{2} \\
& w_{11}^{*}=w_{22} / d+c_{V i}^{2} /\left(C V_{\mathrm{RE}} C_{i}\right)^{2} \\
& w_{12}^{*}=-w_{12} / d+c_{V i} c_{C L i} /\left(C V_{\mathrm{RE}} C_{i}\right)^{2} \\
& w_{22}^{*}=w_{11} / d+c_{C L i}^{2} /\left(C V_{\mathrm{RE}} C_{i}\right)^{2}
\end{aligned}
$$

(h) Compute:

$$
\begin{aligned}
& d^{*}=w_{11}^{*} w_{22}^{*}-w_{12}^{* 2} \\
& g_{11}^{*}=w_{22}^{*} / d^{*} \\
& g_{12}^{*}=-w_{11}^{*} / d^{*} \\
& g_{22}^{*}=w_{11}^{*} / d^{*}
\end{aligned}
$$

(i) Estimate:

$$
\begin{aligned}
V d^{*}= & V d+g_{11} c_{V i} E_{i} /\left(C V_{\mathrm{RE}} C_{i}\right)^{2} \\
& +g_{12} C_{C L i} E_{i} /\left(C V_{\mathrm{RE}} C_{i}\right)^{2} \\
C L^{*}= & C L+g_{12} c_{V i} E_{i} /\left(C V_{\mathrm{RE}} C_{i}\right)^{2} \\
& +g_{22} C_{C L i} E_{i} /\left(C V_{\mathrm{RE}} C_{i}\right)^{2}
\end{aligned}
$$

where $V d^{*}$ and $C L^{*}$ are the values of $V d$ and $C L$ after the feedback adjustment.

(j) Set:

$$
\begin{aligned}
& V d=V d^{*} ; C L=C L^{*} \\
& w_{11}=g_{11} ; w_{12}=g_{12} ; w_{22}=g_{22}
\end{aligned}
$$

\section{(k) Return to step (c).}

It can be seen that the above algorithm is very similar to that proposed by Vozeh et al. for calculating phenytoin kinetic parameters through the Bayesian method [27].

The HP-41 calculator program that we have developed implements the algorithm described above. The program is described in detail in Appendix 2. 
After calculating the Bayesian estimates for $C L$ and $V d$ from the plasma level data, for comparison purposes the program also determines the least-squares estimates for these two parameters. A weighted iterative least-squares procedure (the Gauss-Newton algorithm) is employed to perform the latter function (concentration values are weighted according to $1 / C^{2}$ ).

Finally, the program is able to compute the dosage regimen (maintenance dose and dosing interval) capable of eliciting the desired maximum and minimum plasma concentrations at steady state. The calculation is performed by using the equations described by $\mathrm{Ng}$ [29]. Moreover, the program adopts the same 'practical' dosing intervals reported by $\mathrm{Ng}$.

To demonstrate the clinical application of the HP-41 program, some examples concerning the kinetics of Factor VIII are presented below.

\section{EXAMPLES OF CLINICAL APPLICATION} OF THE PROGRAM: INDIVIDUALIZATION OF FACTOR VIII DOSAGE IN PATIENTS WITH CLASSIC HEMOPHILIA

The need to individualize the dosage of Factor VIII in hemophiliacs has been addressed in recent studies $[23,30]$. Such individualization is useful particularly when a patient is to be treated with a multiple-dose therapy with Factor VIII.

We obtained the population parameters for

\section{TABLE 1}

Population kinetic parameters for a Factor VIII concentrate ${ }^{a}$

\begin{tabular}{llc}
\hline Parameter & Unit & Value \\
\hline$C L_{\text {pop }}$ & $\mathrm{ml} / \mathrm{h} / \mathrm{kg}$ & 4.42 \\
$\mathrm{SD}$ & $\mathrm{ml} / \mathrm{h} / \mathrm{kg}$ & 1.81 \\
$V_{\text {pop }}$ & $\mathrm{ml} / \mathrm{kg}$ & 56.3 \\
$\mathrm{SD}$ & $\mathrm{ml} / \mathrm{kg}$ & 17.1 \\
$C V_{\text {RE }}$ & Dimensionless & 0.21 \\
\hline
\end{tabular}

a The parameters have been estimated retrospectively from the kinetic data of a patient population of 27 hemophiliacs (mean age 29.3 years), for whom 179 data points were available. The Standard Two-Stage method described in Appendix 3 was used to determine these parameters.
TABLE 2

Comparison between the Bayesian parameter estimates generated by the HP-41 and the HP-85/87 programs

\begin{tabular}{|c|c|c|c|c|}
\hline \multirow{3}{*}{$\begin{array}{l}\text { Patient } \\
\text { code }^{a}\end{array}$} & \multicolumn{4}{|c|}{ Bayesian estimates } \\
\hline & \multicolumn{2}{|c|}{ HP-41 program } & \multicolumn{2}{|c|}{ HP-85/87 program } \\
\hline & $\begin{array}{l}C L \\
(\mathrm{ml} / \mathrm{kg} / \mathrm{h})\end{array}$ & $\begin{array}{l}V d \\
(\mathrm{ml} / \mathrm{kg})\end{array}$ & $\begin{array}{l}C L \\
(\mathrm{ml} / \mathrm{kg} / \mathrm{h})\end{array}$ & $\begin{array}{l}V d \\
(\mathrm{ml} / \mathrm{kg})\end{array}$ \\
\hline 1 & 3.41 & 48.6 & 3.47 & 48.2 \\
\hline 2 & 1.77 & 58.8 & 2.15 & 52.1 \\
\hline 3 & 4.17 & 56.4 & 4.16 & 56.3 \\
\hline 4 & 4.24 & 50.2 & 4.22 & 50.0 \\
\hline 5 & 4.77 & 59.4 & 4.79 & 59.5 \\
\hline 6 & 2.27 & 41.2 & 2.55 & 35.4 \\
\hline 7 & 4.23 & 54.6 & 4.22 & 54.5 \\
\hline 8 & 6.68 & 71.0 & 7.08 & 71.0 \\
\hline 9 & 3.89 & 58.4 & 3.88 & 57.8 \\
\hline 10 & 4.28 & 55.4 & 4.28 & 55.4 \\
\hline 11 & 3.91 & 49.4 & 3.91 & 49.2 \\
\hline 12 & 3.16 & 51.2 & 3.26 & 50.2 \\
\hline
\end{tabular}

a Patient's data are given in detail in a previous report [30].

Factor VIII from the data of 27 hemophiliacs treated with a Factor VIII concentrate (KryobulinImmuno) at the Hemophilia Center of the Careggi Hospital (Florence) from January 1982 to June 1984. The Standard Two-Stage method was employed to calculate the population parameters (see Appendix 3). The population mean values for $C L$ and $V d$ are presented in Table 1, along with their standard deviations and the value of $C V_{\mathrm{RE}}$.

To assess the agreement between the parameter estimates generated by the HP-41 and the HP$85 / 87$ programs, we retrospectively analyzed the previously published kinetic data of 12 hemophiliacs treated with Factor VIII [30]. In these patients, a limited number of plasma samples were drawn after a test dose in an attempt to characterize the kinetic behavior of Factor VIII on the basis of the test-dose kinetic data. All patients received a multiple-dose treatment with Factor VIII; the dosage regimen was determined by using the Sawchuk-Zaske method [30].

In the present analysis, two plasma levels drawn approximately 3 and $9 \mathrm{~h}$ after the initial dose were analyzed in each patient and the Bayesian estimates for $C L$ and $V d$ were determined from these two plasma levels. For this purpose, both the 
HP-41 and HP-85/87 programs were used in order to compare the parameter estimates generated by the two programs. The results of this analysis are given in Table 2. It can be seen that the Bayesian parameters estimated by the HP-41 program are consistent with those estimated by the ADVISE program. The data reported in Table 2 were evaluated by linear regression analysis (the HP-41 parameters were regressed on the HP-85/87 parameters). The following results were obtained:

Clearance: regression line $C L_{\mathrm{HP}-41}=-0.092+$ $0.998 C L_{\mathrm{HP}-85}$; correlation coefficient $=0.992$.

Apparent volume of distribution: regression line $V d_{\mathrm{HP}-41}=9.257+0.850 V d_{\mathrm{HP}-85}$; correlation coefficient $=0.963$.

To better illustrate the clinical use of the HP-41 program, the data of Patient 8 are presented in detail. This patient (age 30 years, weight $61 \mathrm{~kg}$, baseline Factor VIII plasma concentration 0.0088 units $/ \mathrm{ml}$ ) received 1000 units of Factor VIII (test dose) for a minor bleeding episode. Two plasma samples were taken after the test dose (Table 3). Before inputting the plasma level data into the calculator program, the kinetic correction for the endogenous synthesis of Factor VIII [26] was performed. Therefore, the baseline Factor VIII plasma level was subtracted from the two measured concentrations. The two time-concentration data points were then analyzed using the HP-41 program. Fig. 1 shows the printed output provided by the calculator.

Another example of clinical application of the program is presented in Fig. 2. This example refers to a hemophilia patient (age 28 years, weight 58 $\mathrm{kg}$ ) who received three Factor VIII doses (Kryobulin-Immuno) prior to application of the

\section{TABLE 3}

Administered dose and measured plasma Factor VIII levels for Patient $8^{\text {a }}$

\begin{tabular}{rll}
\hline \multicolumn{1}{l}{ Hour } & $\begin{array}{l}\text { Dose } \\
\text { (units } / \mathrm{kg} \text { ) }\end{array}$ & $\begin{array}{l}\text { Level } \\
\text { (units } / \mathrm{ml} \text { ) }\end{array}$ \\
\hline 9:00 a.m. & 16.4 & \\
11:45 a.m. & & 0.1589 \\
7:30 p.m. & & 0.0842 \\
\hline
\end{tabular}

a The patient was treated with Kryobulin-Immuno.
INIT.

NEW POP ESTIM?

INST. ABSOR. ?

YES

C4 RE $=0.2100$

HEAN Yd $=56.3860$

ENTER DATA

SDEY Yd $=17.1080$

MEAN $\mathrm{CL}=4.4280$

DAY 1

SDEY $\mathrm{CL}=1.8180$

$H=9.60$

PARAMETER

$D=16.4608$

ESTIMATION

BAY 1

BAYESIAN METHŨ̃

$H=11.45$

$C=8.1591$

$Y d=78.9772$

$\mathrm{Ci}=6.6774$

$T 1 / 2=7.3678$

$H=15.38$

$C=0.8754$

L-S METHOD

$Y d=85.578 c$

$\mathrm{Cl}=7.6026$

$T 1 / 2=7.8024$

SUSR $=1.8958 E-13$

DOSAGE

PREDICTION

BAYESIAN METHOD

PEAK TIME $=9.2590$

DES. $M A S=0.3890$

DES. NIN=0. 1808

$R N D=4.8984$

$\angle D=2 \dot{\theta} .491 \overline{8}$

$M D=12.2951$

PEAK IIHE $=9.2580$

TAU $=12.6990$

PRED. MRX $=0.2530$

PRED. $M I N=0.0838$

NEY PRED. ?

$\mathrm{NO}$

Fig. 1. This figure describes application of the HP-41 program to the kinetic data of Patient 8 . The administered dose and the measured concentrations of Factor VIII are shown on the left of the figure; on the right, the calculated parameter estimates and the suggested dosage regimen (12.2951 units/kg, corresponding to 750 units, every $12 \mathrm{~h}$ ) are reported. The symbols appearing in this figure are explained in Table 4 . The half-life (T1/2) is calculated as $0.693 \mathrm{Vd} / \mathrm{CL}$. 
Bayesian program. Three previous plasma levels of Factor VIII were available for this patient. Since the patient had a baseline Factor VIII level close

INIT. NEH POP ESTIN?

INST. AEGOR. ?

YES

CY RE $=9.2108$

MEAN Yd $=56.3600$

ENTER BATH

SDFY Yd $=17.1900$

MEAN $C L=4.4200$

DAY 1

SDEY $\mathrm{CL}=1.8160$

$H=9.08$

$D=17.2098$

PARAMETER

ESTIMATION

\section{DAY 2}

BAYESIAN METHOD

$Y_{d}=67.3953$

$H=9.98$

$\mathrm{IJ}=8.6809$

$C L=5.1459$

$T 1 / 2=9.078 \mathrm{i}$

DAY 3

L-S METHOD

$Y_{d}=86.8856$

$H=18.80$

$\mathrm{D}=8.6860$

$C L=4.9616$

$T 1 / 2=12.1381$

SHSR $=0.0260$

\section{IAY 1}

$H=15.88$

$C=0.1410$

DAY 2

$H=17.60$

$C=0.1080$

DAY 3

$H=17.00$

$C=8.0820$

\section{JOSAGE}

PREDICTION

BAYESIAN METHOD

PEAK TIME $=0.2590$

DES. MAX $=0.3680$

DES. MIN $=0.1860$

$R N D=4.3100$

LI $=21.5590$

$M D=12.9390$

PEAK TIME $=0.2500$

$T A \mathrm{~J}=12.6960$

PRED. MRX $=0.03167$

PRED. MIN $=0.1291$

NEH PRED. ?

NO

Fig. 2. In this example, the HP-4l program is used to analyze the data of a hemophilia patient with a more complex dosing history. The optimal dosage regimen is determined based on the Bayesian estimates of $C L$ and $V d$. to zero, the kinetic correction for the endogenous synthesis of Factor VIII [26] was not employed. As shown in Fig. 2, the HP-41 program was used to calculate the values of $C L$ and $V d$ through the Bayesian and least-squares methods. The optimal dosage regimen for the patient was then determined using the Bayesian estimates of $C L$ and $V d$.

\section{DISCUSSION}

Over the past few years Bayesian analysis has increasingly been used for individualizing drug dosage regimens. Unfortunately, the previously published programs for applying the approach in clinical practice were generally designed for microcomputers. Although these computers have several important advantages over hand-held calculators in terms of graphics capabilities, storage capacity, and the ability to generate formatted consult reports for inclusion in the patient's medical records, programmable calculators are generally more widely available in many institutions. Thus, the HP-41 program described herein may be of value for routine use.

In order to demonstrate the accuracy of this program we have shown that the parameter estimates obtained with the HP-41 program are very similar to the results obtained using the original ADVISE program. We are currently in the process of assessing the prospective predictive ability of this program to determine Factor VIII maintenance dosing requirements from data available following a test dose. Preliminary results in this area are encouraging.

It is important to note that, although the examples presented herein refer to the kinetics of Factor VIII, this program has general applicability and can be applied to any drug for which the one-compartment model is appropriate (e.g. theophylline and the aminoglycosides).

Finally, it should be stressed that the theoretical basis of the HP-41 program is slightly different from that implemented in the ADVISE program. In the present report, a limited amount of data is given concerning the relative performance of the HP-41 and HP-85/87 programs. Further studies 
are needed, however, to more fully evaluate the HP-41 program.

\section{REFERENCES}

[1] L.B. Sheiner, B. Rosenberg and K.L. Melmon, Modelling of individual pharmacokinetics for computer aided drug dosage, Comp. Biomed. Res. 4 (1972) 441-459.

[2] L.B. Sheiner, S. Beal, B. Rosenberg and V.V. Marathe, Forecasting individual pharmacokinetics, Clin. Pharmacol. Ther. 26 (1979) 294-305.

[3] R.J. Sawchuk, D.E. Zaske, R.J. Cipolle, W.A. Wargin and R.G. Strate, Kinetic model for gentamicin dosing with the use of individual patient parameters, Clin. Pharmacol. Ther. 21 (1977) 362-369.

[4] J.R. Koup, Single-point prediction methods: a critical review, Drug Intell. Clin. Pharm. 16 (1982) 855-862.

[5] S. Pancorbo, S. Davies and J.L. Raymond, Use of a pharmacokinetic method for establishing doses of aminophylline to treat acute bronchospasm, Am. J. Hosp. Pharm. 38 (1981) 851-856.

[6] B.W. Madsen, R.A. Tarala and J.W. Paterson, A hand-held calculator program for individualized dosage adjustment of intravenous theophylline in acute asthma, Eur. J. Clin. Pharmacol. 17 (1980) 393-399.

[7] J.R. Koup, T. Killen and L.A. Bauer, Multiple-dose non-linear regression analysis program: aminoglycoside dose prediction, Clin. Pharmacokinet. 8 (1983) 456-462.

[8] C.C. Peck, W.D. Brown, L.B. Sheiner and B.C. Schuster, A microcomputer drug (theophylline) dosing program which assists and teaches physicians, in: J.T. O'Neil, ed. Proc. 4th Annual Conference on Computers in Medical Care. 2 (1980) 988-991.

[9] A.W. Kelman, B. Whiting and S.M. Bryson, Parameter optimisation in clinical pharmacokinetics, Comput. Programs Biomed. 14 (1982) 239-248.

[10] A.W. Kelman, B. Whiting and S.M. Bryson, OPT: A package of computer programs for parameter optimisation in clinical pharmacokinetics, Br. J. Clin. Pharmacol. 14 (1982) 247-256.

[11] B. Whiting, A.W. Kelman and A.D. Struthers, Prediction of response to theophylline in chronic bronchitis, $\mathrm{Br}$. $\mathrm{J}$. Clin. Pharmacol. 1 (1984) 1-8.

[12] L.B. Sheiner, ADVISE Users Guide (Technical Report of the Division of Clinical Pharmacology, University of California, San Francisco, CA, February 1983).

[13] T.S. Foster and D.W.A. Bourne, Use of a programmable hand-held calculator for clinical pharmacokinetics, Am. J. Hosp. Pharm. 34 (1977) 70-75.

[14] R.G. Buice, The programmable hand-held calculator: a powerful tool in clinical pharmacokinetics, Drug Intell. Clin. Pharm. 13 (1979) 328-333.

[15] J.C. Mitsuoka and R.J. Fleck, Individualized estimation of clearance following a loading dose and continuous intravenous infusion using a programmable calculator, Comput. Programs Biomed. 16 (1983) 21-26.
[16] R.A. Robb, L.A. Bauer ad J.R. Koup, Manual of integrated HP-41C calculator programs for pharmacokinetic calculations (American Society of Hospital Pharmacists, Bethesda, MD, 1982).

[17] M.V. Loertscher, A calculator program for adjusting aminoglycoside regimens that accounts for tissue accumulation in children and adolescents, Drug. Intell. Clin. Pharm. 16 (1982) 563-567.

[18] A. Messori, G. Donati-Cori and E. Tendi, A programmable calculator procedure for parameter estimation according to the two-compartment open model with first order absorption, Farmaco Prat. 38 (1983) 183-190.

[19] A. Messori, G. Donati-Cori and E. Tendi, Pharmacokinetic predictions based on a variable dosage frequency in chronic treatment, Drug Intell. Clin. Pharm. 17 (1983) 290-292.

[20] A. Messori, T. Valenza, G. Zaccara, G. Arnetoli, C. Bartoli, G. Donati-Cori, E. Tendi and R. Zappoli, A new programmable calculator procedure for individualizing phenytoin dosage, Drug Intell. Clin. Pharm. 17 (1983) 890-893.

[21] A. Messori, G. Donati-Cori and E. Tendi, Iterative leastsquares fitting programs in pharmacokinetics for a programmable hand-held calculator, Am. J. Hosp. Pharm. 40 (1983) 1673-1684.

[22] A. Messori, G. Zaccara, T. Valenza, G. Arnetoli, C. Bartoli, G. Donati-Cori, G.C. Muscas and E. Tendi, Comparative analysis of the pharmacokinetic techniques available for individualizing phenytoin dosage, J. Clin. Hosp. Pharm. 8 (1983) 357-365.

[23] G. Longo, M. Matucci, M. Morfini, S. Vannini and A. Messori, A calculator program for individualizing Factor VIII dosage, Drug Intell. Clin. Pharm. 18 (1984) 726-730.

[24] A. Messori, G. Donati-Cori and E. Tendi, A calculator program for least-squares parameter estimation according to the one-compartment kinetic model with zero-order input, Comput. Programs. Biomed. 18 (1984) 119-124.

[25] M. Gibaldi and D. Perrier, Pharmacokinetics (Marcel Dekker, New York, 1982).

[26] M. Matucci, A. Messori, G. Donati-Cori, G. Longo, M. Morfini and E. Tendi, Pharmacokinetics of Factor VIII: $\mathrm{C}$ : appropriateness of the one-compartment model for estimating clearance, Farmaco Prat. 38 (1983) 306-311.

[27] S. Vozeh, K.T. Muir, L.B. Sheiner and F. Follath, Predicting individual phenytoin dosage, J. Pharmacokinet. Biopharm. 9 (1981) 131-146.

[28] L.B. Sheiner and S.L. Beal, Evaluation of method for estimating population pharmacokinetic parameters. III. Monoexponential model: routine clinical pharmacokinetic data, J. Pharmacokinet. Biopharm. 11 (1983) 303-319.

[29] P.K. Ng, Determining aminoglycoside dosage and blood levels using a programmable calculator, Am. J. Hosp. Pharm. 37 (1980) 225-231.

[30] A. Messori, G. Longo, M. Morfini, G. Donati-Cori, M. Matucci, S. Ruffo, E. Tendi and S. Vannini, Individualization of Factor VIII dosage. J. Clin. Hosp. Pharm. 9 (1984) 95-103.

[31] S.L. Beal and L.B. Sheiner, NONMEM Users Guide, 
Parts I and II (Technical Report, Division of Clinical Pharmacology, University of California, San Francisco, CA, 1980).

[32] L.B. Sheiner and S.L. Beal, Evaluation of methods for estimating population pharmacokinetic parameters. I. Michaelis-Menten model: routine clinical pharmacokinetic data, J. Pharmacokinet. Biopharm. 8 (1980) 553-571.

\section{APPENDIX 1: BAYESIAN ESTIMATION OF THE PARAMETERS OF THE ONE-COM- PARTMENT MODEL WITH ZERO-ORDER ABSORPTION}

A function of the HP-41 program allows the user to select the one-compartment model with zero-order input when necessary. Use of such a kinetic model is needed when the drug is administered by constant rate intravenous infusion or by the oral route.

The one-compartment model with zero-order input is based on the following equation:

$$
\begin{aligned}
C_{\mathrm{p}}= & \frac{D \cdot \exp (-[C L / V d][t-P T])}{C L \cdot P T} \\
& \times(1-\exp (-[C L / V d][P T]))
\end{aligned}
$$

where $t$ is the time elapsed since the start of the intravenous infusion or, in the case of the oral route, the time elapsed since oral dosing; and $P T$ is the duration of the constant rate intravenous infusion or, in the case of the oral route, the period over which absorption occurs (peak time).

From the above equation it appears that, if one has to use the program for drugs administered by the oral route, the drug absorption must be assumed to be a zero-order process. This is a reasonable approximation for many drugs and should not introduce expressive error.

In the HP-41 program, the Bayesian estimation of $C L$ and $V d$ on the basis of the above model is performed by using the algorithm described in Section 2.2 for the one-compartment model with instantaneous absorption. The only differences are the following: at steps $(e)$ and $(f)$, the values of $C_{f i}, c_{V i}$, and $C_{C L i}$ are calculated according to equations:

$$
C_{f i}=\sum_{j=1}^{r}\left(D_{j} \cdot \exp \left(-[C L / V d]\left[t_{C i}-t_{D j}-P T\right]\right)\right)
$$

$$
\begin{aligned}
& \times \frac{(1-\exp (-[C L / V d][P T]))}{(C L)(P T)} \\
c_{V i}= & \sum_{j=1}^{r}\left[\left(D_{j} \cdot \exp \left(-[C L / V d]\left[t_{C i}-t_{D j}-P T\right]\right)\right.\right. \\
& \times\left(\left(t_{C i}-t_{D j}\right)(1-\exp (-[C L / V d][P T]))\right. \\
& \left.-P T)) / V^{2} \cdot P T\right] \\
c_{C L i}= & \sum_{j=1}^{r}\left[D_{j} \cdot \exp \left(-[C L / V d]\left[t_{C i}-t_{D j}-P T\right]\right)\right. \\
& \times\left(\left(C L\left(t_{D j}-t_{C i}\right)-V d\right)\right. \\
& \times(1-\exp (-[C L / V d][P T]))+C L \cdot P T) \\
& \left./\left(C L^{2} \cdot V d \cdot P T\right)\right]
\end{aligned}
$$

It should be noted that $P T$ is a parameter which is not estimated by the program, but is assigned by the user.

The value of $P T$ is assumed to be the same for all the doses that have been administered to the patient. Furthermore, as shown by the above equations, the program is unable to process concentration data which have been measured during the time period over which the zero-order absorption occurs. Thus, in the case of oral administrations, concentration values measured after a dose but before the subsequent peak must not be used for the Bayesian feedback; similarly, in the case of the constant-rate intravenous administrations, concentration values measured during an infusion cannot be processed. Thus, care should be taken in recommending sampling times for peak levels after oral dosing of a drug.

\section{APPENDIX 2: USER INSTRUCTIONS FOR OPERATING THE PROGRAM}

\section{General information}

The program can be run on a Hewlett-Packard HP-41CV calculator equipped with an 'extended 
TABLE 4

Symbols used in user instructions and their explanations ${ }^{\text {a }}$

\begin{tabular}{|c|c|}
\hline Symbol & Explanation \\
\hline PT & $\begin{array}{l}\text { Peak time, i.e. the period over which the zero- } \\
\text { order absorption occurs. }\end{array}$ \\
\hline H & $\begin{array}{l}\text { Time at which a dose has been given or a } \\
\text { plasma level has been measured. All time val- } \\
\text { ues must be entered as date and hour: the day } \\
\text { on which the first dose was given is arbitrarily } \\
\text { denominated as 'day 1'; the code for all subse- } \\
\text { quent days is defined accordingly. }\end{array}$ \\
\hline DCODE & Day code (see 'H'). \\
\hline D & Dose. \\
\hline C & Plasma drug concentration. \\
\hline Vd & Apparent volume of distribution. \\
\hline $\mathrm{CL}$ & Clearance. \\
\hline$T \frac{1}{2}$ & Half-life. \\
\hline DES.MAX & $\begin{array}{l}\text { Desired peak plasma concentration at steady } \\
\text { state. }\end{array}$ \\
\hline DES.MIN & $\begin{array}{l}\text { Desired trough plasma concentration at steady } \\
\text { state. }\end{array}$ \\
\hline LD & Loading dose. \\
\hline MD & Maintenance dose. \\
\hline RND & $\begin{array}{l}\text { Amount by which the calculated values of LD } \\
\text { and MD are rounded. }\end{array}$ \\
\hline TAU & Dosing interval. \\
\hline PRED.MAX & $\begin{array}{l}\text { Predicted peak plasma concentration at steady } \\
\text { state. }\end{array}$ \\
\hline PRED.MIN & $\begin{array}{l}\text { Predicted trough plasma concentration at } \\
\text { steady state. }\end{array}$ \\
\hline SWSR & $\begin{array}{l}\text { Sum of squared residuals between experimen- } \\
\text { tal and fitted values of concentration. }\end{array}$ \\
\hline
\end{tabular}

a The population parameters are denoted by the following symbols: CV RE, coefficient of variation for the intraindividual and model misspecification variability error; MEAN Vd, mean value of the apparent volume of distribution; SDEV $\mathrm{Vd}$, standard deviation of the apparent volume of distribution; MEAN CL, mean value of the clearance; SDEV $\mathrm{CL}$, standard deviation of the clearance.

functions module' (HP 82180A) and an 'extended memory' module (HP 82181A). The use of a printer is optional. The program is split into three subprograms called: program BAYES, program LS, and program DOSE. These three subprograms must be loaded into the 'extended memory' of the calculator. This extended memory is a continuous one and loading operations must therefore be performed once only. The program can be stored on 11 magnetic cards. The typical running time for the program is approximately $5 \mathrm{~min}$.

\section{Program listings}

Listing for programs BAYES, LS and DOSE are available from the authors on request.

\section{Initialization of the program}

Before using the program, the user must clear the whole main program memory of the calculator. Moreover, if 'assignments' to keys ' $A$ ', 'shift A', 'B', 'C', 'D', 'E', 'shift E', 'F', 'G', 'H', 'I' or 'J' have been done previously, these assignments must be cleared.

\section{User instructions}

All symbols used are given in Table 4. User instructions for operating the program are reported in Table 5. These instructions are intended for use with a printer attached to the calculator. However, the program can also be used without a printer. Under this circumstance, the user instructions are slightly different. A copy of these instructions can be requested from the authors.

Note. As previously stated, individualized calculation of the dosage capable of eliciting the desired peak and trough levels is obtained by using the equations described by $\mathrm{Ng}$ [29]. Through these equations, the program determines the dosage regimen (maintenance dose and dosing interval) that is likely to produce the desired peak and trough levels at steady state. In detail, the program first performs exact calculation of the dosage regimen (maintenance dose and dosing interval) that produces the desired peak and trough levels. The calculated values of both the maintenance dose and dosing interval are then rounded for practical purposes. Finally, the peak and trough steady-state levels that result from the 'practical' dosage regimen are predicted.

Furthermore, a loading dose is also calculated by the program. The loading dose is the dose that is capable of producing the desired peak and trough levels after the first administration. The latter function of the program provides, however, little clinical utility because the calculated loading dose is appropriate only if enough time has elapsed since the last dose for the plasma level to approach 
TABLE 5

User instructions ${ }^{\text {a }}$

\begin{tabular}{|c|c|c|c|c|}
\hline Step & Display & Procedure & Enter & Press \\
\hline 1 & & Initialize & & 'shift a' b \\
\hline 2 & $\begin{array}{l}\text { INST. ABSOR.? } \\
\text { YES }=1 \text { NO }=0\end{array}$ & $\begin{array}{l}\text { Answer } 1 \text { (YES }=\text { instantaneous } \\
\text { absorption) or } 0(\mathrm{NO}= \\
\text { zero-order absorption) }\end{array}$ & 1 or 0 & $' R / S '$ \\
\hline 3 & PEAK TIME = ? & $\begin{array}{l}\text { Enter PT (only when the zero-order } \\
\text { absorption is selected) }\end{array}$ & PT & $' \mathbf{R} / \mathbf{S} '$ \\
\hline 4 & ENTER DATA & & & \\
\hline $5 a$ & & $\begin{array}{l}\text { Enter DCODE (only if a new } \\
\text { day is selected) }\end{array}$ & DCODE & ${ }^{\prime} \mathrm{A}$ 'b \\
\hline $5 b$ & & Enter $\mathbf{H}$ & $\mathbf{H}$ & ' $B$ ' b \\
\hline $5 c$ & & Enter D & $\mathbf{D}$ & ' $\mathrm{C}$ 'b \\
\hline 6 & & Repeat steps $5 a-5 b-5 c$ for all subsequent & & \\
\hline $7 \mathrm{a}$ & & $\begin{array}{l}\text { Enter DCODE (only if a new } \\
\text { day is selected) }\end{array}$ & DCODE & $' A{ }^{\prime} b$ \\
\hline $7 \mathrm{~b}$ & & Enter $\mathrm{H}$ & $\mathbf{H}$ & $' D$ 'b \\
\hline $7 \mathrm{c}$ & & Enter C & C. & $' E^{\prime} b$ \\
\hline 8 & & Repeat steps $7 a-7 b-7 c$ for all subsequent & vels ${ }^{\mathrm{c}}$ & \\
\hline 9 & & Correct input errors, if any & & \\
\hline 10 & & Press ' $F$ ' & & $' F{ }^{\prime} b$ \\
\hline 11 & $\begin{array}{l}\text { NEW POP ESTIM? } \\
\mathrm{YES}=1 \mathrm{NO}=0\end{array}$ & $\begin{array}{l}\text { Answer } 1 \text { ( }=\text { YES) to enter popula- } \\
\text { tion estimates different from } \\
\text { those stored in the program memory; } \\
\text { answer } 0(=\mathrm{NO}) \text { if the population } \\
\text { estimates must not be changed. } \\
\text { The population estimates are } \\
\text { printed }\end{array}$ & 1 or 0 & $' \mathrm{R} / \mathrm{S} '$ \\
\hline 12 & & $\begin{array}{l}\text { The program calculates the Bayesian } \\
\text { estimates for } V d, C L, \text { and } T 1 / 2 \text { and } \\
\text { then the least-squares estimates } \\
\text { for the three parameters and the } \\
S W S R \text { value. The results are printed }\end{array}$ & & \\
\hline 13 & & Start computation of dosage regimens & & ' J'b \\
\hline 14 & $\mathrm{BAY}=1 \mathrm{LS}=2 ?$ & $\begin{array}{l}\text { Answer } 1 \text { ( = BAY) to select Bayesian } \\
\text { prediction of dosage; } \\
\text { answer } 2(=\mathrm{LS}) \text { to select least- } \\
\text { squares prediction }\end{array}$ & 1 or 2 & $' \mathrm{R} / \mathrm{S} '$ \\
\hline 15 & PEAK TIME $=?$ & $\begin{array}{l}\text { Enter PT. This parameter must } \\
\text { always be input. Select a short } \\
\text { PT value when the model with } \\
\text { instantaneous absorption is being } \\
\text { used }\end{array}$ & PT & $' \mathrm{R} / \mathrm{S}$ ' \\
\hline 16 & DES. MAX $=$ ? & Enter DES.MAX & DES. MAX & $' \mathbf{R} / \mathbf{S} '$ \\
\hline 17 & DES. $\mathrm{MIN}=$ ? & Enter DES.MIN & DES. MIN & $' \mathbf{R} / \mathrm{S}$ ' \\
\hline 18 & $\mathrm{RND}=?$ & Enter RND & RND & $' \mathbf{R} / \mathrm{S} '$ \\
\hline 19 & & $\begin{array}{l}\text { The dosage regimen is } \\
\text { calculated and printed }\end{array}$ & & \\
\hline 20 & $\begin{array}{l}\text { NEW PRED? } \\
\text { YES }=1 \text { NO }=0\end{array}$ & $\begin{array}{l}\text { Answer } 1(=\text { YES }) \text { to start a } \\
\text { new dosage prediction; } \\
\text { otherwise, answer } 0(=\mathrm{NO})\end{array}$ & 1 or 0 & $' R / S '$ \\
\hline 21 & END & $\begin{array}{l}\text { This message is printed after } \\
\text { the final dosage prediction }\end{array}$ & & \\
\hline
\end{tabular}


zero. As a result, the calculated loading dose should be administered only if at least five patient's Factor VIII half-lives have elapsed since administration of the last dose; otherwise, the calculated loading dose will initially elicit plasma concentrations exceeding the desired values.

\section{APPENDIX 3: USE OF THE HP-41 PROGRAM FOR ESTIMATING POPULATION KINETIC PARAMETERS ACCORDING TO THE STANDARD TWO-STAGE METHOD}

Two methods are commonly used for estimating population pharmacokinetic parameters: the NONMEM method [31] and the Standard TwoStage (STS) method [28,32].

The STS method has been shown to be less precise and less accurate than NONMEM in estimating population kinetic parameters fom routine pharmacokinetic data [28]. This is particularly apparent when routine data characterized by few data points per individual are to be analyzed. The STS method is, however, useful in situations where there is much data per individual. As pointed out by Sheiner [28], it can work fairly well in these situations.

Briefly, the STS method requires that each individual's data be fitted separately to the kinetic model (first stage) and that the individual parameter estimates be combined to yield the population parameters (second stage).

\section{First stage}

Three kinetic parameters $\left(C L_{i}, V d_{i}\right.$ and the sum of weighted squared residuals) must be calculated from each individual's data by weighted nonlinear least-squares regression analysis. Our HP-41 program can be used for this purpose because the weighted least-squares subroutine allows the above parameters to be estimated. In our program, the concentration data are weighted according to the squared reciprocal of the measured concentrations (weight $=1 / C^{2}$ ); as a result, the fitting procedure yields a sum of weighted squared residuals ( $S W S R$ ), which is a dimensionless quantity.

\section{Second stage}

The individual values of $C L_{i}, V d_{i}$, and $S W S R_{i}$ are combined so as to yield the population parameters $C L_{\text {pop }}, V_{\text {pop }}, \mathrm{SD}_{\mathrm{CL}}, \mathrm{SD}_{\mathrm{V}}$ and $C V_{\mathrm{RE}}$.

The population parameters are estimated as follows: $C L_{\text {pop }}$ and $V_{\text {pop }}$ are determined as the arithmetic averages of the individual $C L_{i}$ and $V d_{i}$ values, respectively, while $S_{C L}$ and $S_{V}$ are estimated from the standard deviations of the values of $C L_{i}$ and $V d_{i} . C V_{\mathrm{RE}}$ is calculated from the following equation [28]:

$C V_{\mathrm{RE}}=\frac{\sqrt{\sum} S W S R_{i}}{\left(N_{\text {pairs }}-2 N\right)}$

where $N_{\text {pairs }}$ is the total number of time-concentration data pairs over all individuals and $N$ is the number of individuals. $C V_{\mathrm{RE}}$ is a dimensionless quantity.

TABLE 5 (continued)

\footnotetext{
a The 'size' of the program is 137 . This number of registers is allocated to data storage automatically. Before using the program, the BAYES subprogram must be loaded from extended memory into main memory. This loading operation must not be performed if program BAYES is already present in main memory. No other program must be present in main memory.

b The key must be pressed with the calculator in User mode.

c The number of measured plasma levels and the number of administered doses must be less than 25 .

d The procedure to correct an erroneous input is as follows: a Table with the identification codes for the storage registers containing the values of $D_{j}, t_{D j}, C_{i}$ and $t_{C i}$ must first be examined (this Table is available from the authors on request). The key 'shift E' must then be pressed in User mode; the calculator asks (REG?) the code for the register containing the erroneous input; such a code must be entered, followed by the key 'R/S'. Finally the calculator asks (NEW VALUE?) the correct value and such a value must be entered followed by the key ' $R / S$ '.

c To use population estimates other than those stored in program memory, the procedure is as follows: after each input request of the calculator, the appropriate population parameter must be entered followed by the ' $R / S$ ' key.
} 